\title{
Effect of Information and Communication Technology on Self- Efficacy and Academic Achievement of Students
}

\section{A R T I C L E I N F O}

\section{Article Type}

Original Research

\section{Authors}

Balali F.* $M S C$,

Ahmadi Tabatabaei S.V. ${ }^{1} M D-P h D$,

Hassani A.H. ${ }^{2}$ MSC

How to cite this article Balali F, Ahmadi Tabatabaei S V, Hassani A H. Effect of Information and Communication Technology on Self-Efficacy and Academic Achievement of Students. Health Education and Health Promotion. 2018 ;6(3):97-102.
*Tropical \& Infectious Diseases Research Centre, Kerman University of Medical Sciences, Kerman, Iran

${ }^{1}$ Health Research Center, Futures Studies in Health Institute, Kerman University of Medical Sciences, Kerman, Iran

${ }^{2}$ Petroleum Engineering, Department, Chemical Engineering \& Analytical Science Faculty, University of Manchester, Manchester, England

\section{Correspondence}

Address: Health Education \& Promotion Department, Deputy of Health, Kerman University of Medical Sciences, Jomhoori Eslami Blvd, Kerman, Iran. Postal Code: 7618174765 Phone: +98 (34) 31215752

Fax: +98 (34) 32114231

f.balali@yahoo.com

\section{Article History}

Received: August 20, 2017

Accepted: June 02, 2018

ePublished: September 09, 2018

\section{A B S T R A C T}

Aims Considering the evolution of schools and the growth of smart schools, the aim of the present study was to compare the self-efficacy and academic performance of students in conventional and smart schools.

Materials \& Methods This cross-sectional descriptive-analytic study was conducted in Kerman, Iran, in 2015. 300 students of 8th grade studying in Kerman (145 smart school student and 155 conventional school students) were selected by multi-stage sampling method. Data were collected by a standardized academic self-efficacy questionnaire of Jinks-Morgan and analyzed using independent t-test, linear regression, Pearson correlation test and SPSS 20 software.

Findings Academic achievement in conventional and smart schools was statistically different. So that students of smart schools had better academic achievement than ordinary schools $(p=0.0001)$. While the self-efficacy of the two groups did not differ significantly. There was a significant direct correlation between students' academic achievement and their self-efficacy score $(r=0.159, \mathrm{p}=0.006)$. Also, there was a significant statistical difference, according to the type of school, occupation, and education level of parents $(\mathrm{p}<0.0001)$.

Conclusion The academic self-efficacy of students in the two groups do not differ, students of smart schools have the higher academic achievement. School smartness and high self-efficacy will improve students' academic achievement.

Keywords Schools; Information Technology; Self-Efficac; Educational Status

\section{CIT A T I O N L I N KS}

[1] Comparing school connectedness, academic motivation and academic achievement between smart school students and traditional school ... [2] The main reasons for the lack of correct formation of smart schools in Mazandaran province and presenting solutions for their development ... [3] A study on the strengths, weaknesses, opportunities and threats of ... [4] The survey of the development challenges ... [5] Assessment of smart middle schools establishment in Semnan province from ... [6] Study of general and academic self-efficacy of students and its relationship ... [7] The relationship between personality characteristics and ... [8] A brief questionnaire for measuring ... [9] Educational vitality and perception of family communication ... [10] The effectiveness of smart schooling on ... [11] Technology's edge: The educational benefits of ... [12] The effects of ICT use in teaching and learning on students' achievement in science subject in a primary ... [13] Predictors of academic achievement of student ICT teachers with different ... [14] ICT and diversity in learners' attitude on smart ... [15] Effects of an intelligent web-based English instruction system on students' academic ... [16] Compare social and selflearning skills between traditional and smart schools in high ... [17] Self-efficacy in Internetbased learning environments: A literature ... [18] The effect of ICT- based teaching methods in creating sustained learning in experimental science course in third grade ... [19] The effect of ICT- based teaching methods ... [20] Investigating of the role of ICT on academic performance of ... [21] Comparing educational self-concept \& the rate of learning in the students of normal and smart high ... [22] A survey of the status of smart schools based on standards and comparison of its students academic performance and critical ... [23] Evaluation of impact of smart schools on academic achievement of high school's student in ... [24] Children's perceived academic selfefficacy: An ... [25] Investigating of the relationship between academic self-efficacy and academic achievement in second grade high school girl students in Tehran ... [26] Investigation of measure of decrease and increase of academic achievement when ... [27] Compare Self regulated larning and achievement of students of tradition and smart school and compare ... [28] Introducing ICT in schools in England: Rationale and ... 


\section{Introduction}

The emergence of new phenomena and inventions in any era has affected all aspects of human life (Economic, social, cultural and educational). In the present day, with the advent and development of information and communication technology, the developments of the world, centered on information, are expanding with increasing momentum [1].

Supposedly, smart schools are the key to approach new technology. In smart schools, using electronic face-to-face learning, an intelligent educational, and a comprehensive/combinational approach system and by keeping the physical space of the school, teacher, and student, educational services to students are being made [2].

In these schools, compared to conventional schools, more information technology is used, and it is attempting to solve educational problems with new technologies, including problems related to lack of computer and information knowledge and problems with conventional methods of teacher training [3]. The way of teaching in these schools makes each student understand the content theoretically and practically, and know if s/he faces a problem in the future, where the required resources to access information for solving that problem will be [4]. Students learn how to extract their information through information networks, how to think about them, and how to utilize their findings to solve their problems and develop their communities [5].

In this regard, the concept that students have of their own will affect their efforts and advancements. The understanding of individuals from their own ability to do work and activity is called self-efficacy [6]. Strong predictive and determinant self-efficacy is a level of progress that learners achieve. In other words, self-efficacy is considered as a powerful predictor of progress and academic success [7]. Academic self-efficacy is a key structure for improving learning and academic achievement, and in relation to the individual's ability to manage learning activities, encompass learning topics and meet academic expectations [8]. Students who develop strong academic self-efficacy beliefs can better manage their learning [9].

In recent years, extensive studies have been conducted concerning the effect of electronic training and its effects on the learning and academic achievement of students. As an example, Ong, with examining the differences and effects of education in Malaysian smart schools showed that students' efficacy in smart schools is higher than that of ordinary schools [10]. Increase in academic achievement and the motivation of students' learning are the most important achievements of these schools, and the smart schools are considered as the place where digital technology is used for teaching. [1]. The results of a survey of 1600 students from 17 schools in three major cities in the United
States, was indicated that the performance of students in the experimental group (Trained in the computer lab) was significantly better than the control group (Trained in the conventional way) [11]. The study of the relationship between information and communication technology and academic achievement, education and learning in primary schools in Malaysia [12] and research results in Turkey [13] also indicated a positive relationship between academic achievement and teaching methods using information and communication technology. Hamzah and Embi's smart class academic achievement was higher than that of students studying in regular schools [14]. The systematic analysis of student scores and the results of research vocabulary tests (The Effect of an Intelligent Web Learning System on Students' Academic Performance), showed the positive effect of this educational system for high school students [15].

The meta-analysis findings of more than 1,000 empirical studies from the US Department of Education indicate that students were more efficiently trained in online learning than traditional methods [16].

Tsai et al., in a review of the effectiveness of Internet-based learning environments concluded that self-efficacy has a positive impact on students' learning using the Internet [17].

Most domestic studies also indicate the positive impact of information and communication technology on academic achievement. The findings of Najafi [18] studies in high school students in Ardabil, Soleymanpour et al. [19] in secondary school students in Ramsar, Daeizadeh et al. [20] in high school students in Khash, Hosseinpour et al. [21] in conventional and smart high school in Tehran, Hakimzadeh et al. [1] in high school students in Isfahan, Heidari et al. ${ }^{[22]}$ in conventional and smart high schools in Yazd, Dortaj et al. [23] in pre-college students of smart and conventional schools of Lorestan Province showed that learning based on the information and communication technology is more effective than the conventional method. They also confirmed the impact of technology-based teaching methods on academic achievement.

Anyway, the use of computers on the one hand, by increasing the speed and flexibility of time and space, has provided many opportunities for the spread of science, and on the other hand, by reducing interactions and face-to-face communications, has created concerns for reducing human relations [1]. Self-efficacy has a significant role in creating individual differences in the range of academic performance, and academic achievement is also an important indicator for the evaluation of educational systems.

The aim of the present study was to compare the self-efficacy and academic performance of students 
in conventional and smart schools.

\section{Instruments and Methods}

This cross-sectional descriptive-analytic study was conducted in Kerman, Iran, in 2015. The statistical community included all 8th-grade students in Kerman high schools. Because smart schools use more information technology than ordinary schools, the smartness of the school was considered to be the criterion of information technology. Three hundred students, 145 students from 2 smart schools and 155 students from 2 ordinary schools as statistical sample were collected by multi-stage sampling method. Any school which has used new technologies for at least two years was considered as a smart school. Also, any ordinary school lacking smart and computerized education system was deemed as a conventional school.

The data collection tool comprised three parts: Demographic characteristics, the mean of the previous year and Jinks-Morgan (JMES) standardized self-efficacy questionnaire [24]. The toolkit of the questionnaire's reliability coefficient was reported at 0.82 . Validity and reliability of the questionnaire have already been approved in Iran [25].

This questionnaire has 30 questions. Questions in this questionnaire has been designed based on the Likert scale and have four options, including "fully agree" (4 points), "somewhat agree" (3 points), "somewhat disagree" (2 points) and "completely disagree" (1 point). The questionnaire has a maximum score of 120 . The higher score was considered as more academic self-efficacy. In order to measure students' academic achievement, the average of students' scores in the previous year was used.

In detail, after obtaining necessary licenses and setting an arrangement with the selected schools, and after explaining the goals and nature of the research for the participants, by communicating and gaining trust with the consent of the students, the questionnaires were distributed in the presence of the researcher and immediately after completion were collected. It should be noted that in order to observe the ethics, the research questionnaires were designed nameless and there was no compulsory for participation.

The descriptive statistics such as mean, standard deviation and analytical statistics of $t$ two independent samples and linear regression were used to analyze the data. Correlation between variables was examine by Pearson correlation test. The Independent Samples $t$ Test was used for comparing the self-efficacy and academic achievement of students in smart and ordinary schools. Data were analyzed by SPSS 20 software.

\section{Findings}

50.7 of the fathers of these students (152 people) had free occupation and $46.0 \%$ (138) were employed and 3.3\% (10 students) did not have father.

The level of education for $34.7 \%$ of fathers (104 people) was diploma and $38.3 \%$ (115 people) of them had higher academic degrees and 27.0\% (81 people) were under the diploma.

$70.7 \%$ (212) of the mothers were housewives and $24.3 \%$ (73) were employees and 5.0\% (15 people) had other jobs or variable income.

$41.0 \%$ (123) were mothers with a diploma and $31.7 \%$ (95 people) had mothers with university education and $27.3 \%$ (82 people) were under the diploma.

There was a significant statistical difference, according to the type of school, occupation, and education level of parents $(\mathrm{p}<0.0001)$.

The mean academic self-efficacy score of all students was $87.55 \pm 7.92$ and the mean academic achievement was $18.67 \pm 1.29$.

There was a significant difference between the academic achievement of the students in smart schools and ordinary schools. Smart school students had better academic achievement than ordinary schools. However, there was no significant difference between the academic self-efficacy of students in smart schools and ordinary schools (Table 1).

There was a significant direct correlation between students' academic achievement and their selfefficacy score $\left(r=0.159 ; r^{2}=0.25 ; p=0.006\right)$.

Table 1) Comparison of the average of academic achievement and academic self-efficacy of the studied samples according to the type of school (145 students of smart school and 155 students of conventional school)

\begin{tabular}{lccccc}
\hline \multicolumn{1}{c}{ Variables } & $\begin{array}{c}\text { Smart } \\
\text { schools }\end{array}$ & $\begin{array}{c}\text { Conventional } \\
\text { schools }\end{array}$ & p-Value & t-Value \\
\hline $\begin{array}{l}\text { Educational } \\
\text { self-efficacy }\end{array}$ & $88.77 \pm 7.61$ & $87.34 \pm 8.22$ & 0.639 & 0.470 \\
$\begin{array}{l}\text { Academic } \\
\text { achievement }\end{array}$ & $19.14 \pm 0.84$ & $18.24 \pm 1.47$ & 0.0001 & 6.354 \\
\hline
\end{tabular}

\section{Discussion}

The aim of the present study was to compare the self-efficacy and academic performance of students in conventional and smart schools.

The results of the present study showed no significant difference in self-efficacy between two groups of students. In other words, there was no difference between self-efficacy of students of smart schools and ordinary schools in Kerman. Several studies have investigated the self-efficacy of different groups, including academic self-efficacy in students; yet, the similar study that compared the educational self-efficacy of smart school students (with information technology) to ordinary schools in Iran was not available. Nevertheless, Tsai et al. studied the impact of learners' self-efficacy on their learning in Internet-based environments. They reviewed 46 articles between 1999 and 2009 about 
the effectiveness of Internet-based learning environments, assessment of the effectiveness of self-efficacy in Internet-based education, and the relationship between learners' general self-efficacy and Internet-based education. They concluded that self-efficacy has a positive effect on students' learning using Internet [17]. The non-meaningful difference in students' self-efficacy of these two groups may be because of the impact of external factors outside the school.

Nowadays, due to the growth of computer technologies, information is easily and quickly accessible to everyone, and the school is not the only framework for the teacher to transfer knowledge, skills, and values to students anymore; the economic, social, and cultural frameworks and mass media also play a decisive role [5].

Therefore, easy access to information and communication technology such as computers, the Internet, tablets, mobiles, etc. (Which is now readily available to students) and curiosity, which is a feature of adolescence, has increased the ability and self-efficacy of students in all fields including education. Students may reach higher capability and academic efficacy out of school. In order to understand the impact of these external factors, further research considering the different environmental elements is needed.

The study of the difference between academic achievement in smart schools and ordinary schools in Kerman showed that students of smart schools have significantly higher degree of academic achievement than those in ordinary schools. The results obtained from this study were in agreement with the results of many other studies, including Hakimzadeh et al. [1], Ong [10], Zidan [12], Hamzah and Embi [14], Najafi [18], Daeizadeh et al. [20], Heydari et al. [22], Dortaj et al. [23] while were not consistent with Esmaeil Pour [26] and Vasefian [27].

Hammond in a study about the educational system in the UK concluded that information and communication technology had a small effect on schools while the impact of information and communication technology cannot be ignored. This impact should be evaluated in the context of what is expected from a realistic perspective. Future advances in the use of information and communication technology need to be further assessed, and the multi-dimensional nature of technology must be considered [28].

Anyway, information technology in smart schools increases the motivation, interest in learning, and ultimately the academic achievement of students by providing facilities, engaging learners, and not having time and place constraints.

In the present study, according to the results of linear regression test, there was a significant direct correlation between students' academic achievement and their self-efficacy score. Based on many studies, academic self-efficacy and academic achievement are two-way links, and the level of progress in learning based on information and communication technology leads to an increase in the efficacy of individuals [25]. Therefore, providing a suitable environment for the emergence of positive and higher efficacy will lead to increased academic achievement in the future. Therefore, given the mission of the educational system to create the proper platform for the growth and excellence of intellectual capital [22], it is imperative that authorities and practitioners create appropriate environments for information technology in order to enable the use of these educational environments for all Students.

In this study, after receiving a list of schools and obtaining education permits, we referred to schools for data collection. Unfortunately, we noticed that the vast majority of schools that were considered smart in education were just a name for being smart; in other words, they were semi-smart. In fact, only a percentage of their infrastructure was modified for being smart. Only one or more classes were equipped with smart boards and one or more limited teachers used these smart boards (For example, mathematics or physics etc.). According to the definition of smart schools, they were neither smart nor ordinary. Finally, a few non-smart or normal schools and relatively smart schools were identified. All students in these classes were enrolled in the study due to the limited number of students in the 8th-grade of these schools. This was one of the limitations of this study.

There were also some other limitations. In this study, the average of the year before was considered as the criterion for students' academic achievement. It seems that the average of the previous year is not the best indicator for academic achievement. Findings will be more reliable if there are standardized tests for academic achievement.

Since the self-study and self-reporting questionnaire was used to collect self-efficacy data and even academic achievement, the samples may be influenced by the time, place, and even the high number of questions and answers. Students might have answered the questions according to that specific time, place, or position, and also avoided to reply correctly and accurately. This factor is one of the limitations of all questionnaire studies. The strengths of this study include gathering data collectively (referring to the students' class), and the co-operation and passion of education and school officials to achieve the results of this study.

Considering the positive impact of using information technology on students' progression and the positive relationship between self-efficacy and academic achievement, qualitative and quantitative development of smart schools in conjunction with some interventions to increase students' selfefficacy is necessary.

In this study, the variables studied were limited and 


\section{1}

therefore the following items are suggested:

1) In future studies, additional variables can be examined; also the consequences of these variables in the lives of students and other community groups can be studied.

2) The impact of direct and indirect factors and also the effect of demographic factors on academic selfefficacy and academic motivation can be investigated.

3) The main method of data collection in this research was a questionnaire; although, this method predominates in most studies, it is suggested that information of each variable gathers using several different methods in order to obtain the outcomes with more confidence and generalization.

\section{Conclusions}

The academic self-efficacy of students in the two groups do not differ, students of smart schools have the higher academic achievement. School smartness and high self-efficacy will improve students' academic achievement.

Acknowledgements: Authors would like to thank the authorities of Shahid Bahonar University, the University of Medical Sciences, Kerman Education Organization, the directors of the schools and students who have collaborated with them on the implementation of this project.

Ethical permissions: The Ethical code of the present study is Ir.kmu.Rec.1393.335.

Conflicts of interests: The Authors state that there are no conflict of interests.

Authors' Contribution: Balali F. (First author), Introduction author/ Original researcher/ Discussion author (40\%); Ahmadi Tabatabaei S.V. (Second author), Methodologist/ Assistant researcher/ Statistical analyst/ Discussion author (30\%); Hassani A.H. (Third author), Assistant researcher/ Discussion author (30\%)

Funding/Support: This article is a part of the master thesis of Shahid Bahonar University of Kerman and is sponsored by the Deputy of Research and Technology of Kerman University of Medical Sciences.

\section{References}

1- Hakimzadeh R, Aboalghasemi Najaf Abadi M, Nejati F. Comparing school connectedness, academic motivation and academic achievement between smart school students and traditional school students in Esfahan. J Educ. 2012;19(1):151-70. [Persian]

2- Mohajeran B, Ghaleei AR, Hamzeh Robati M. The main reasons for the lack of correct formation of smart schools in Mazandaran province and presenting solutions for their development (from the viewpoints of ICT experts). Media. 2013;4(2):13-23. [Persian]

3- Zamani BE, Ghassab Pour B, Jabal Ameli J. A study on the strengths, weaknesses, opportunities and threats of Iranian smart schools. J Educ Innov. 2011;9(36):79-100.
[Persian]

4- Mahmoodi J, Nalchiger S, Ebrahimi SB, Sadeghi Moghadam MR. The survey of the development challenges smart schools. J Educ Innov. 2008;7(27):61-78. [Persian]

5- Afzalkhani M, Ghods S. Assessment of smart middle schools establishment in Semnan province from the administrators and teachers view. Inf Commun Technol Educ Sci. 2011;2(1):23-39. [Persian]

6- Zeainali Pour H, Zarei E, Zandiniya Z. Study of general and academic self-efficacy of students and its relationship with academic achievement. J Educ Psychol Stud. 2009;6(9):13-28. [Persian]

7- MirSharafalDin AR, Hosseini M. The relationship between personality characteristics and academic selfefficacy. J Hum Sci Res. 2017;3(18):57-68. [Persian]

8- Muris P. A brief questionnaire for measuring selfefficacy in youths. J Psychopathol Behav Assess. 2001;23(3):145-9.

9- Dehghanizadeh MH, Hossein Chari M. Educational vitality and perception of family communication model, self-efficacy mediator role. Educ Learn Stud. 2012;4(2):2147. [Persian]

10- Ong ET, Ruthven K. The effectiveness of smart schooling on students' attitudes towards science. Eurasia J Math Sci Technol Educ. 2009;5(1):35-45.

11- Barrow L, Markman L, Rouse CE. Technology's edge: The educational benefits of computer-aided instruction. Am Econ J Econ Policy. 2009;1(1):52-74.

12- Zidan AA, Ismail I, Spain R, Kumutha K. The effects of ICT use in teaching and learning on students' achievement in science subject in a primary school in Malaysia. Malays J Distance Educ. 2011;13(2):19-32.

13- Deryakulu D, Büyüköztürk Ş, Özçınar H. Predictors of academic achievement of student ICT teachers with different learning styles. Int Sch Sci Res Innov. 2009;3(10):1951-7.

14- Hamzah MI, Embi MA, Ismail A. ICT and diversity in learners' attitude on smart school initiative. Procedia Soc Behav Sci. 2010;7:728-37.

15- Jia J, Chan Y, Ding Z, Bai Y, Yang B, Li M, et al. Effects of an intelligent web-based English instruction system on students' academic performance. J Comput Assist Learn. 2013;29(6):556-68.

16- Ghanaatpishe M, Salehi M. Compare social and selflearning skills between traditional and smart schools in high school students. Q New Appr Edu Manag. 2018;9(33):73-88. [Persian]

17- Tsai CC, Chuang SC, Liang JC, Tsai MJ. Self-efficacy in Internet-based learning environments: A literature review. Educ Technol Soc. 2011;14(4):222-40.

18- Najafi H. The impact of Information Technology (IT) on the academic achievements of high school students of Ardebil city (2005-2006). Peyke Noor J. 2008;6(3):82-93. [Persian]

19- Soleymanpoor J, Khalkhali A, Raayat Konande Fallah L. The effect of ICT- based teaching methods in creating sustained learning in experimental science course in third grade secondary school students. Inf Commun Technol Educ Sci. 2011;1(2):77-94. [Persian]

20- Daeizadeh H, Hosseizadeh B, Ghaznavi MR. Investigating of the role of ICT on academic performance of high school students. Q J Educ Leadersh Adm. 2010;4(4):81-97. [Persian]

21- Hosseinpoor L, Allahvirdiyani K, Motallebi Nejad AR, Momeni Rad A, Mohammdjami H. Comparing educational self-concept \& the rate of learning in the students of 
Effect of Information and Communication Technology on Self-Efficacy...

normal and smart high schools in Tehran. Procedia Soc Behav Sci. 2011;15:3002-4.

22- Heidari M, Vaziri M, Adli F. A survey of the status of smart schools based on standards and comparison of its students academic performance and critical thinking with public schools. Inf Commun Technol Educ Sci. 2014;4(2):149-73. [Persian]

23- Dortaj F, Lakpour E, Bohlooli A. Evaluation of impact of smart schools on academic achievement of high school's student in Lorestan province. J Technol Educ. 2013;8(2):133-41. [Persian]

24- Jinks J, Morgan V. Children's perceived academic selfefficacy: An inventory scale. Clear House J Educ Strateg Issues Ideas. 1999;72(4):224-30.

25- Karimzadeh $M$, Mohseni $N$. Investigating of the relationship between academic self-efficacy and academic achievement in second grade high school girl students in Tehran (trends of mathematical and human sciences). Womens Stud Sociol Psychol. 2006;4(2):29-45. [Persian] 26- Esmaeil Pour M, Shookoor Z, Naderi Far V. Investigation of measure of decrease and increase of academic achievement when establish smart schools. $5^{\text {th }}$ National Conference and 2nd International Conference on Learning and electronics education. Tehran: Amirkabir University of Technology; 2009.

27- Vasefian F, Naghsh S. Compare Self regulated larning and achievement of students of tradition and smart school and compare relationship between two variables. J Curr Res. 2014;4(1):103-16. [Persian]

28- Hammond M. Introducing ICT in schools in England: Rationale and consequences. $\mathrm{Br} \mathrm{J}$ Educ Technol. 2014;45(2):191-201. 